\title{
Proximal Gastrectomy in a Case of Giant Gastric Liposarcoma and a 5-Year Follow-Up
}

\author{
Petr Lochman ${ }^{a, b}$ Stanislav Rejchrt ${ }^{c} \quad$ Jiří Páral $^{\mathrm{a}, \mathrm{b}}$ \\ aDepartment of Field Surgery, Faculty of Military Health Science, University of Defence, \\ Hradec Králové, Czech Republic; bepartment of Surgery, Charles University Faculty of \\ Medicine and University Hospital, Hradec Králové, Czech Republic; '2nd Department of \\ Internal Medicine - Gastroenterology, Charles University Faculty of Medicine and \\ University Hospital, Hradec Králové, Czech Republic
}

\section{Keywords}

Gastric liposarcoma $\cdot$ Proximal gastrectomy $\cdot$ Follow-up

\begin{abstract}
Even though liposarcomas account for $10-20 \%$ of all mesenchymal malignancies, they are extremely rarely located in the stomach. We report the case of a female patient with gastric liposarcoma. CT revealed a giant hypoechogenic tumour subcardially on the posterior gastric wall. Endoscopic tumour resection by piecemeal technique was done, and a lipoma was confirmed on histopathological examination. A recurrent bleeding tumour was proven 6 weeks later. The patient underwent an open proximal gastrectomy with pyloroplasty, and liposarcoma was surprisingly revealed in the resected specimen, finally. Five years later, our patient had been without recurrence or any somatic difficulties. The CT finding of a submucosal fatty tumour with heterogeneous density within the gastric wall should raise the suspicion for liposarcoma. The goal is the surgical removal of the tumour with sufficient margins ensuring $\mathrm{R} 0$ resection.

\section{Introduction}

Even though liposarcomas account for $10-20 \%$ of all mesenchymal malignancies, they are extremely rarely located in the stomach. We report the case of a female patient with large gastric liposarcoma that was finally managed by proximal gastrectomy. The patient has been alive without any sign of recurrence since 2012. 
Fig. 1. Bleeding submucosal tumour of the stomach below the esophagogastric junction (endoscopic retrograde view).
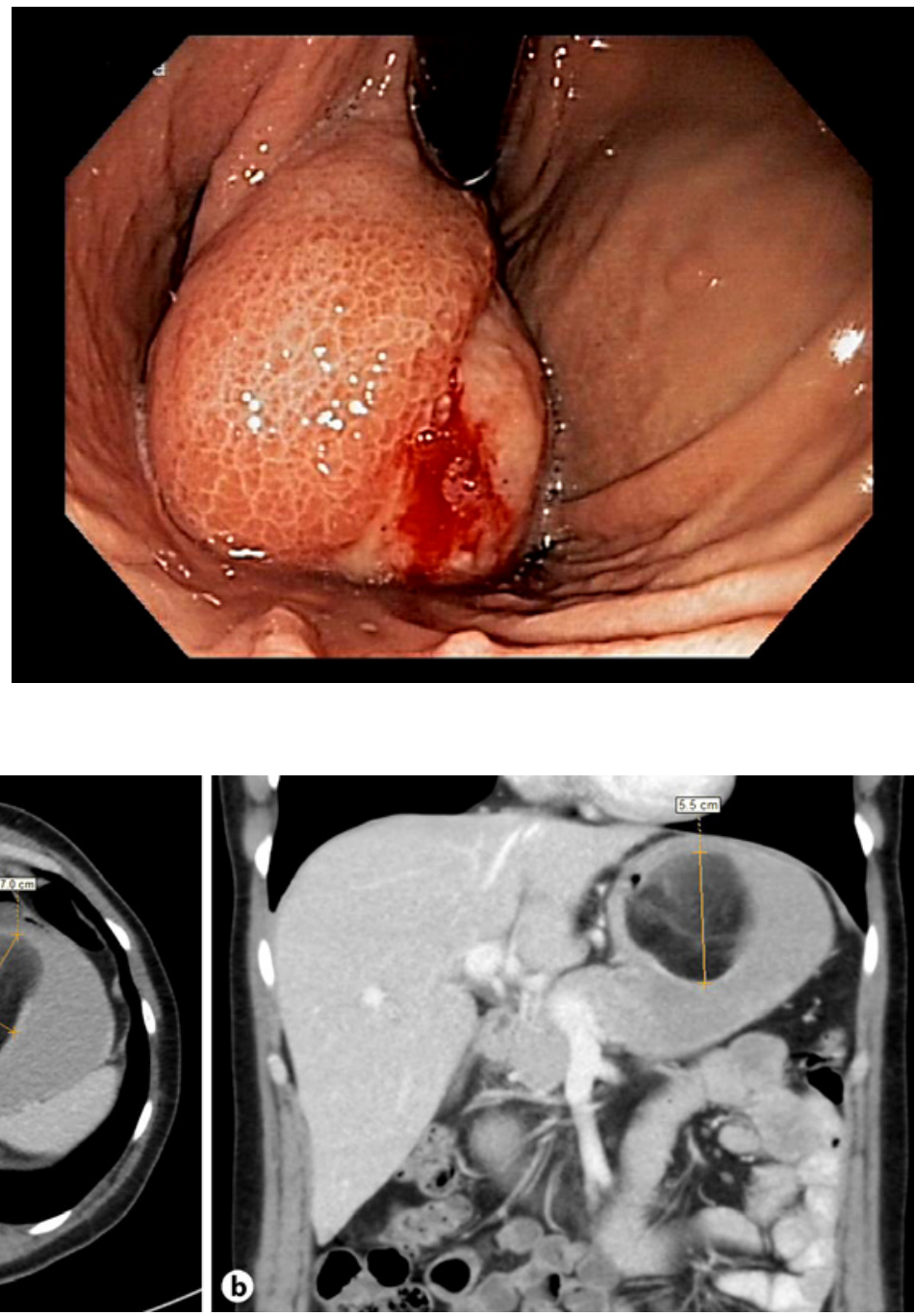

Fig. 2. Fatty tumour within the gastric wall (a transversal and $\mathbf{b}$ frontal view image).

\section{Case Report}

In November 2011, a 48-year-old woman, who had been periodically checked for submucosal tumour below the esophagogastric junction since 2004, was presented with melena and anaemia (haemoglobin level $7.5 \mathrm{~g} / \mathrm{dL}$ ) (Fig. 1). CT revealed a giant hypoechogenic tumour subcardially on the posterior gastric wall, size $70 \times 50 \times 55 \mathrm{~mm}$ (Fig. 2). Endoscopic tumour resection by piecemeal technique was done under general anaesthesia in December 2011, and a lipoma was confirmed on histopathological examination. A recurrent bleeding tumour was proven 6 weeks later by endoscopy. The patient was indicated for surgery. A laparoscopic resection of the tumour on the anterior wall of the stomach just below the cardia was performed using linear staplers. A well-differentiated liposarcoma, lipoma-like variant, was discovered. The resection margin was assessed as R1. The patient underwent an open proximal gastrectomy with pyloroplasty 2 months later with no signs of residual tumour in the resected specimen.

During the postoperative period, balloon and bougie dilations were repeatedly performed as well as an endoscopic pyloromyotomy in November 2015, due to persistent problems with 
gastric emptying. The patient received supplementary enteral nutrition until November 2016 because of unsufficient peroral intake with ongoing body weight loss. Five years later, our patient had been without recurrence or any somatic difficulties. Compared to her pre-operative status, the significant body weight loss was still present (58 vs. 47 kg; BMI 20.1 vs. 16.3). Her laboratory results did not show any malnutrition, however. Moreover, they were better than pre-operatively (total protein $67.3 \mathrm{vs.} 73.2 \mathrm{~g} / \mathrm{L}$; albumin $38.2 \mathrm{vs.} 52.3 \mathrm{~g} / \mathrm{L}$ ). The level of haemoglobin was $13.3 \mathrm{~g} / \mathrm{dL}$.

\section{Discussion}

Liposarcomas, although the most common mesenchymal malignancy of all, are rarely seen in the gastrointestinal tract. Since first described in 1941 by Abrams et al., only 37 cases of gastric liposarcoma have been published in English in the literature to date [1]. Most liposarcomas were located in the antrum or lesser curvature, esophagogastric junction involvement as in our case was reported only once [2].

The peak incidence for gastric liposarcomas is in the 6th and 7th decade of life. The etiology remains unclear; however, some patients have a positive family history for any soft tissue tumour that suggests genetic factors may play a role in the origin of gastric liposarcomas [3]. Gastric liposarcomas originate from undifferentiated mesenchymal cells in the submucosal and muscular layers of the stomach wall, and an exophytic growth is typical [1, 4]. The characteristic histological feature of the tumour is a presence of immature fat cells and lipoblasts [4]. Histologically, they are classified and divided into 5 subtypes (well-differentiated/dedifferentiated, myxoid, round cells, and pleomorphic) $[1,3,5]$.

There are no characteristic clinical findings, and patients may remain asymptomatic for a long period - which was also the case of our patient who had been periodically checked by endoscopy for 7 years due to likely gastric lipoma. Symptoms depend predominantly on the location and size of the tumour and the presence of ulceration [6]. Mechanical obstruction, gastrointestinal bleeding and palpable mass belong to the most common symptoms. Generally, nonspecific symptoms are the main reason for a delayed diagnosis.

The final diagnosis is mostly based on a histopathological examination of the resected specimen. Endoscopic biopsies may fail because the submucosa remains intact as long as the tumour is not ulcerating. The most effective examination is a CT scan. The presence of a wellcircumscribed fatty dense tumour within the submucosa with enhanced areas supports the diagnosis [7]. CT can also exclude any potential secondary lesions and lymphadenopathy. A relation between CT findings and histopathological type was reported: well-differentiated liposarcomas show a classic heterogeneous density, liquid cystic changes are typical for myxoid type and round cells, and pleomorphic types are characterized by a non-specific solid structure [7, 8]. Differential diagnosis includes lipoma, stromal tumour (gastrointestinal stromal tumour), lymphoma, peritoneal liposarcoma, or hepatic metastasis adjacent to the stomach [9-11].

The treatment method of choice is surgical removal. The type of resection depends on the location and size of the tumour and varies from a small excision to total gastrectomy. A wide resection margin to ensure R0 is highly recommended, as well. Lymphadenectomy seems not to be necessary because of a lack of lymph node involvement. Currently, there is no evidence of efficacy of chemotherapy or radiotherapy even though few reported patients have been treated with these methods [1]. Due to a high risk of local recurrence, adjuvant therapy might be beneficial. 


\section{Conclusion}

The CT findings of a submucosal fatty tumour with heterogeneous density within the gastric wall should raise the suspicion for liposarcoma. The goal is a surgical removal of the tumour with sufficient margins ensuring R0 resection.

\section{Statement of Ethics}

The patient has given informed consent to publish her case including images. The paper complies with the guidelines for human studies in accordance with the World Medical Association Declaration of Helsinki.

\section{Disclosure Statement}

The authors have no conflicts of interest to declare.

\section{Funding Sources}

This work was supported by A long-term organization development plan 1011 - Clinical fields (Faculty of Military Health Sciences 2017-2020).

\section{Author Contributions}

P.L. wrote the main text of the manuscript, S.R. provided photographs, S.R. and J.P. did the final revision of the text. All authors approved the final version of the manuscript.

\section{References}

1 Kang WZ, Xue LY, Wang GQ, Ma FH, Feng XL, Guo L, et al. Liposarcoma of the stomach: report of two cases and review of the literature. World J Gastroenterol. 2018;24(25):2776-84.

2 Askan G, Bagci P, Hameed M, Bastürk O. Dedifferentiated liposarcoma of the gastroesophageal junction. Turk Patoloji Derg. 2018;34(1):104-7.

3 Matone J, Okazaki S, Maccapani GN, Amancio TT, Filippi RZ, Macedo AL. Giant gastric lipossarcoma: case report and review of the literature. Einstein (Sao Paulo). 2016;14(4):557-60.

4 Tepetes K, Christodoulidis G, Spyridakis ME, Nakou M, Koukoulis G, Hatzitheofilou K. Liposarcoma of the stomach: a rare case report. World J Gastroenterol. 2007;13(30):4154-5.

5 Bostanoglu A, Yildiz B, Kulacoglu S, Avsar F. Primary liposarcoma of the stomach. Turk J Gastroenterol. 2013; 24(2):167-9.

6 Elhjouji A, Jaiteh L, Mahfoud T, Belhamidi S, Bounaim A, AitAli A, et al. Giant gastric liposarcoma: a fatal exceptional location. J Gastrointest Cancer. 2016;47(4):482-5.

7 López-Negrete L, Luyando L, Sala J, López C, Menéndez de Llano R, Gomez JL. Liposarcoma of the stomach. Abdom Imaging. 1997;22(4):373-5.

8 Ferrozzi F, Bova D, Garlaschi G. Gastric liposarcoma: CT appearance. Abdom Imaging. 1993;18(3):232-3.

9 Kim MJ, Gu M, Choi JH, Kim SW, Kim KO. Gastric liposarcoma presenting as a huge pedunculated polyp. Endoscopy. 2014;46(Suppl 1 UCTN):E441-2.

10 Hamdane MM, Brahim EB, Salah MB, Haouas N, Bouhafa A, Chedly-Debbiche A. Giant gastric lipoma mimicking well-differentiated liposarcoma. Gastroenterol Hepatol Bed Bench. 2012;5(1):60-3.

11 Ferrozzi F, Tognini G, Bova D, Pavone P. Lipomatous tumors of the stomach: CT findings and differential diagnosis. J Comput Assist Tomogr. 2000;24(6):854-8. 